\title{
A infografia baseada em dados brutos: design e programação proporcionando uma melhor análise da informação
}

The infographics based on raw data: design and programming providing better information analysis

\section{Gustavo Guilherme da Matta Caetano Lopes}

Mestrando do Programa de Comunicação e Linguagem da Universidade Tuiuti do Paraná - UTP; pós-graduado em Comunicação e Informação, pela Universidade Tecnológica Federal do Paraná - UTFPR; graduado em Comunicação Social, pelas Faculdades Integradas Hélio Alonso - Facha, do Rio de Janeiro; professor do Curso de Comunicação Social da Faculdade Internacional de Curitiba Facinter.

\section{Juliana Cristina Faggion Bergmann}

Doutora em Sciences du Langage, pela Université Lumière Lyon 2, França; master (DEA - diplôme d'études approfondies) pela mesma instituição; mestre e graduada em Letras, pela Universidade Federal do Paraná - UFPR; professora do Departamento de Metodologia de Ensino do Centro de Ciências da Educação da Universidade Federal de Santa Catarina - MEN/CED/UFSC.

\begin{abstract}
Resumo
Leitores de jornalismo esportivo são, possivelmente, os mais sedentos por novas análises e novos usos para dados estatísticos. As novas tecnologias de Player Tracking geram dados precisos de movimentação de jogadores em campo, que abrem novas possibilidades de análise, dados que, na Copa do Mundo de 2010, foram disponibilizados pela Fifa em seu site. A infografia jornalística está, cada vez mais, usando recursos de programação para transformar grandes volumes de dados em gráficos comprensíveis. Serão analisados o uso desses dados pela infografia do jornal Gazeta do Povo, de Curitiba, no Paraná, assim como as possíveis mudanças no método de trabalho que este tipo de fonte de informação acarreta.
\end{abstract}

Palavras-chave: base de dados, infografia, jornalismo.

\begin{abstract}
Sports journalism readers are possibly the most hungry for new statistics uses and analysis. New technologies for Player Tracking generate accurate data handling of players on the field, opening new possibilities for analysis, once FIFA at the World Cup 2010 made all the data available on the official website. The infographic journalism are now using programming resources to convert large volumes of data in intelligible graphics. We analyze how the Gazeta do Povo newspaper from Curitiba - PR use this database and how this type of information make changes in the work methods.
\end{abstract}

Keywords: database, infographic, journalism. 


\section{A infografia baseada em dados brutos: design e programação proporcionando uma melhor análise da informação}

\section{A tecnologia e os dados disponibilizados pela FIFA}

A tecnologia de Player Tracking utiliza câmeras de vídeo de alta definição para gerar imagens que serão processadas por um computador.

No caso da empresa Stats, que presta o serviço para a Fifa, são usadas três câmeras para filmar o campo, e uma câmera extra para detectar outros movimentos, como substituição de jogadores. As três câmeras são usadas para gerar um único vídeo, no qual o movimento de cada jogador é rastreado. A partir do caminho percorrido por cada um deles, são obtidos dados como a velocidade, a distância percorrida, as partes do campo nas quais houve mais movimentação, entre quais jogadores houve mais passes etc. Os dados computados pelo sistema são disponibilizados pela Fifa em até 15 minutos depois de cada jogo, apresentados em planilhas em formato PDF.

\section{Infografia ou visualização?}

Será tomada a definição de infografia dada por Pereira Junior: "O infográfico é a informação jornalística em linguagem gráfica. Não é ilustração. É arte estatística, imagem informativa, notícia visual, a expressão iconográfica de fatos, a explicação do funcionamento de algo ou a conceituação de um objeto." (PEREIRA JunIOR, 2006: 125).

Dentro das várias definições de Pereira Junior (2006), é possível destacar que as que mais se relacionam com os gráficos da Copa da Gazeta do Povo são "arte estatística", por serem gráficos gerados completamente a partir de estatísticas; e "expressão iconográfica de fatos", por ser o "iconográfico" o único modo de apresentar os fatos.

Neste caso, os fatos são os dados gerados pelos sistemas de Player Tracking, que precisam ser interpretados, traduzidos ou compilados, neste caso, para uma linguagem gráfica a fim de serem visualmente entendidos. Para o resultado dessa tradução, optou-se pelo uso do termo "visualização" utilizado por Ben Fry (2008). Esse termo define bem as expressões gráficas de dados que não somente ficariam mais fáceis de entender graficamente, mas seriam impossíveis de ser compreendidos de outra maneira, como é o caso dos dados gerados pelos sistemas de Player Tracking.

Essa visualização apresenta muitas vantagens, sendo "boa para limpeza dos dados, para explorá-los, para identificar tendências e agrupamentos, para encontrar padrões locais, para avaliar modelos de representação de gráficos e para apresentar resultados." (Unwin, Theus \& Hofmann, 2006: 2).

No entanto, para a realização desse tipo de gráfico, o ideal seria contar com os dados brutos, o que possibilitaria mai- ores opções de análise, cruzamento de informações e descoberta de fatos que merecessem ser destacados.

Como a Fifa disponibiliza somente os dados sobre o número de passes entre os jogadores, números estes previamente editados possivelmente também pelo software de Player Tracking, há uma restrição natural das possibilidades de análise e, apesar de os dados minimamente editados não impedirem novas interpretações, esses números ainda são suficientemente brutos e permitem que sejam analisados e explorados novamente por vários ângulos.

\section{Definindo padrões}

De Pablos (1999), em suas conclusões sobre o que chamou de "mecânica infográfica", afirmou que "Existe un fenómeno comunicativo, cada vez más valioso, de selección mecánica de prototipos de infografías, según una colección de modelos ya existentes y editados anteriormente." (DE PABLos, 1999: 160).

É comum, em departamentos de infografia de jornais ou revistas, existirem gráficos previamente preparados, com padrões definidos por infografistas ou por quem cuidou do projeto gráfico da infografia. É o caso dos gráficos estatísticos mais comuns, como o de pizza ou o de barras. Todavia, estas formas básicas não são suficientes para conjuntos de dados com características peculiares. Como afirmou Ben Fry: "A tool that has generic uses will produce only generic displays, which can be disappointing if the displays do not suit your data set. Data can take many interesting forms that require unique types of display and interaction [....]' (FRY, 2008: vii).

Para a escolha destes "unique types of display", foi feita uma pesquisa sobre quais dados seriam disponibilizados pela Fifa, e que análises poderiam ser feitas a partir deles. Como resultado, percebeu-se que poucos dados poderiam ser visualizados através de gráficos simples; a maioria deles solicitou - ou permitiu - visualizações específicas, derivadas de tipos de gráficos já conhecidos, como será visto a seguir.

Os diversos tipos de gráficos foram agrupados em infográficos maiores, que foram concebidos como dashboards (termo inglês para painel de automóvel, em referência à possibilidade de ficarem todas as informações reunidas em um único lugar), agrupando todas as informações estatísticas do jogo e servindo de apoio às matérias do jornal (Figura 1). Percebe-se, assim, que, para cada tipo de informação, foi selecionado um tipo de gráfico que se adequasse aos dados disponíveis e que servisse para evidenciar os fatos nele contidos. 


\section{A infografia baseada em dados brutos: design e programação proporcionando uma melhor análise da informação}

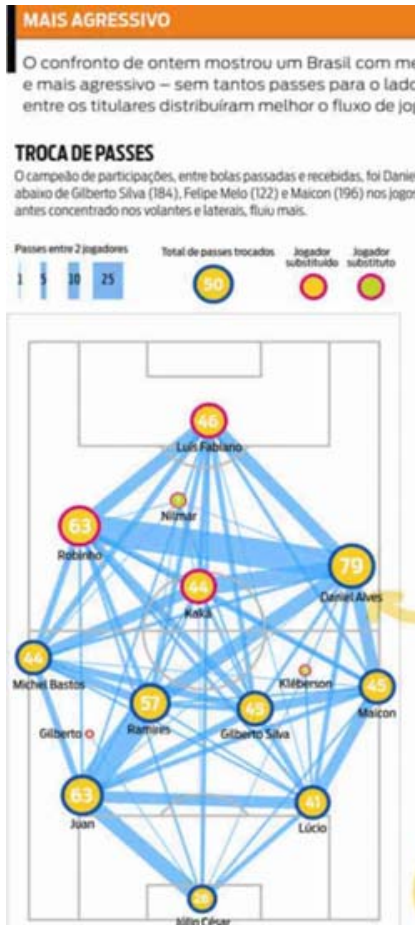

JOGADOR POR JOGADOR
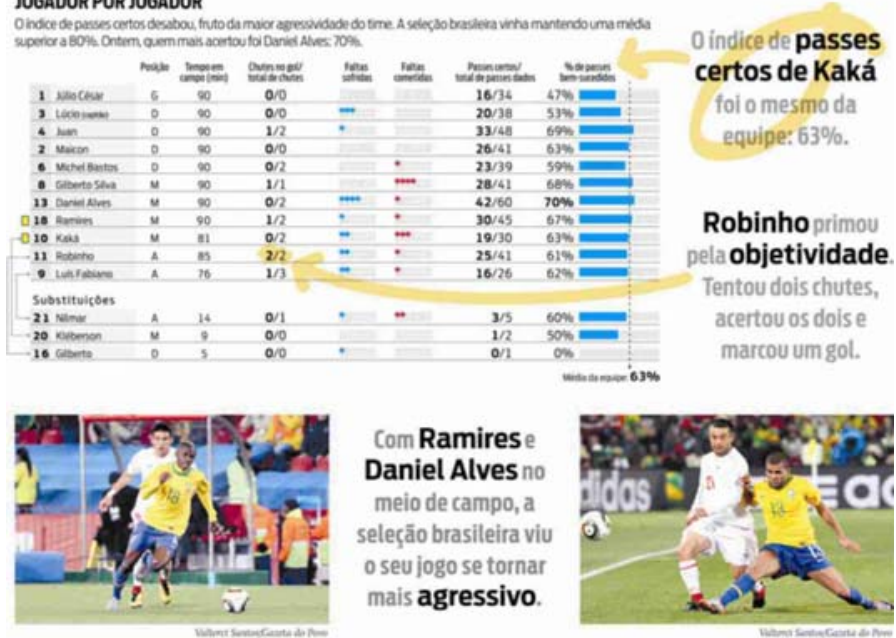

DADOS GERAIS

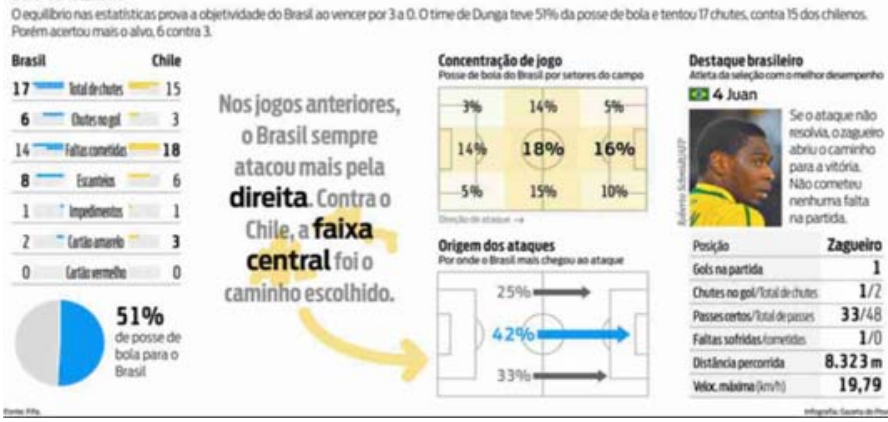

Figura1: Infográfico publicado na Gazeta do Povo, no dia 29 de junho de 2010

Fonte: jornal Gazeta do Povo.

\section{Principais tipos de gráficos utilizados}

\subsection{O mapa de passes}

Permite analisar o desempenho da equipe como um todo. Mostra entre quais jogadores houve maior número de passes, o rendimento de cada um e também qual parte do campo foi mais usada, o que pode ser interpretado para analisar a estratégia do técnico e do time (Figura 2).
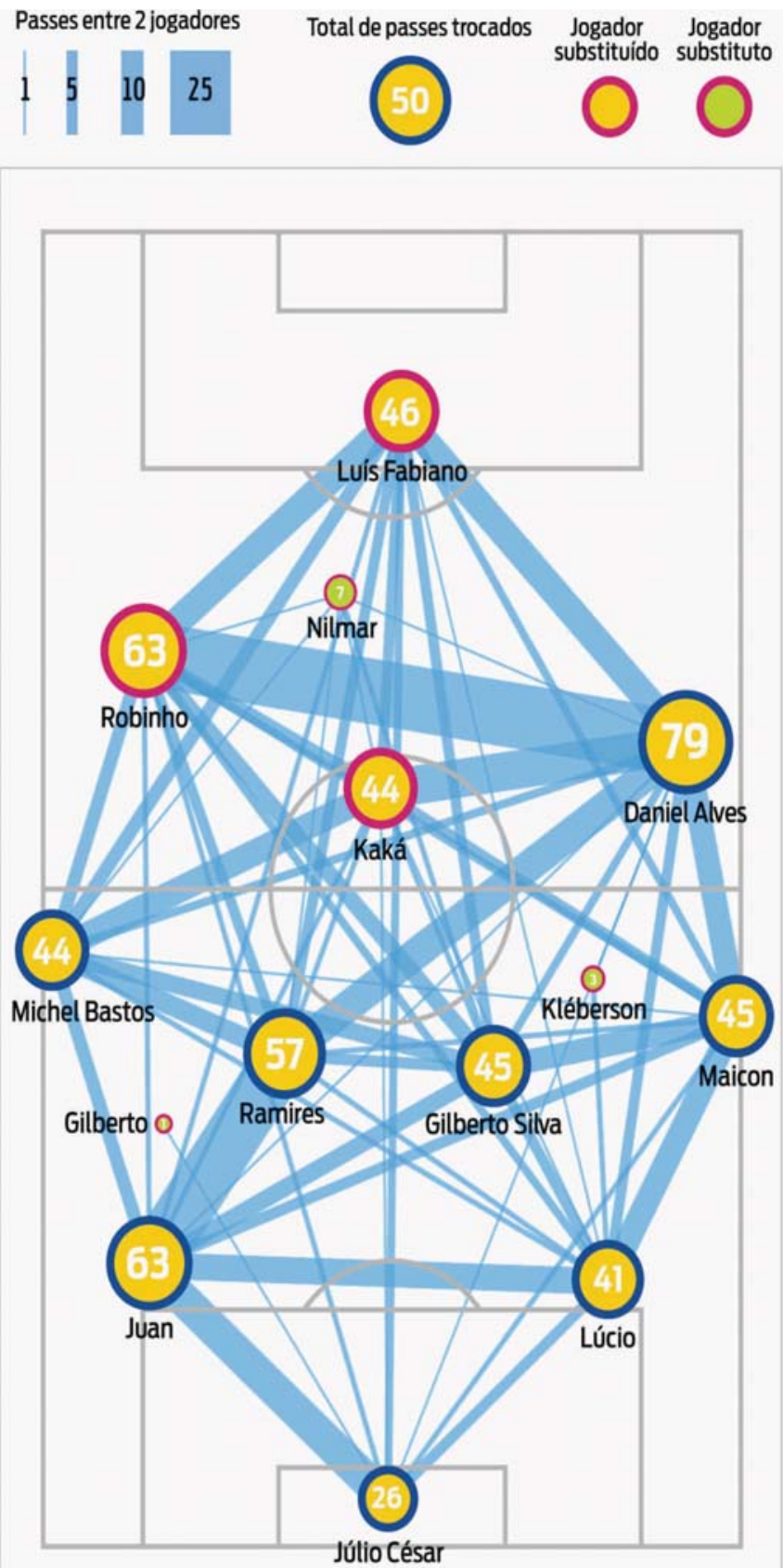

Figura 2: Mapa de passes, o principal gráfico do "Dashboard" (zoom da Figura 1) 


\section{A infografia baseada em dados brutos: design e programação proporcionando uma melhor análise da informação}

O modelo do gráfico foi baseado nos diagramas produzidos pelo infografista espanhol Chiqui Esteban, que trabaIhou no Jornal Público e no site <http://www.lainformacion. com>, ambos espanhóis. Ele citou como inspiração um gráfico publicado pelo jornal austríaco Der Standard durante a Copa do Mundo de 2006. Para a elaboração desses gráficos, quando não havia a possibilidade de usar estatísticas fornecidas por empresas de Player Tracking, ele próprio anotava as informações ao assistir à partida na televisão.

Podem ser rastreados vários tipos de gráficos dos quais o mapa de passes se apropria. O primeiro é o que Yves Deforge chamou de "sociograma" (Figura 3), um gráfico criado para expressar relações (DEFORGE, 1991: 137). Ele partiu de uma tabela de relações, assim como o mapa de passes, que parte de uma versão simplificada dos dados da Fifa. No exemplo mostrado por Deforge (1991), podese ver ainda que os elementos que se relacionam estão organizados em círculo; no mapa de passes, cada jogador é representado na posição aproximada em que joga dentro do campo.

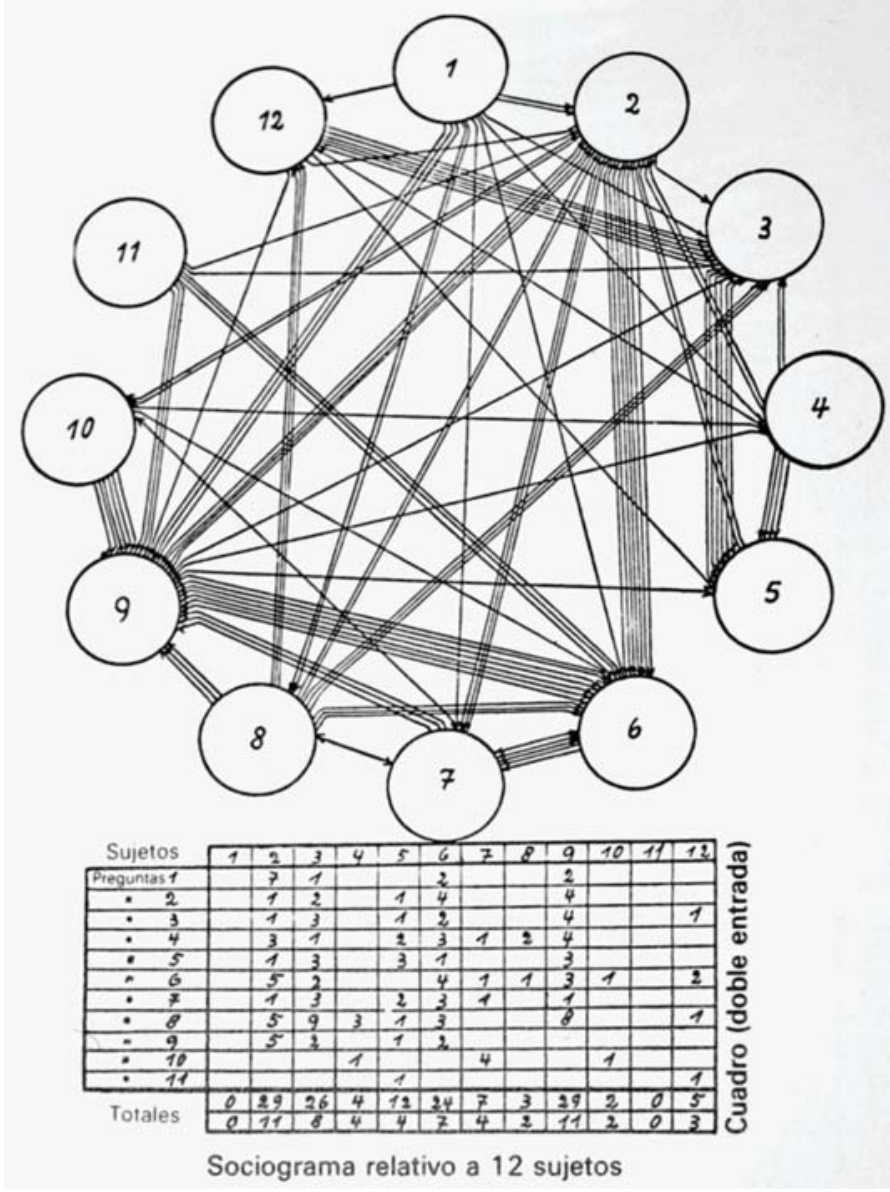

Figura 3: Sociograma expressando relações entre 12 pessoas Fonte: exemplo retirado do livro Imagen didáctica (DeForGE, 1991: 25).
A espessura das linhas é diretamente proporcional ao número de passes trocado entre dois jogadores. Um antecedente é o famoso gráfico das tropas de Napoleão durante a invasão à Rússia (Figura 4), feito em 1869 pelo francês Charles Minard e apontado como "possivelmente o melhor gráfico estatístico jamais desenhado" (TUFTE, 2001: 48). Nele, a espessura das linhas representa a quantidade de soldados vivos.

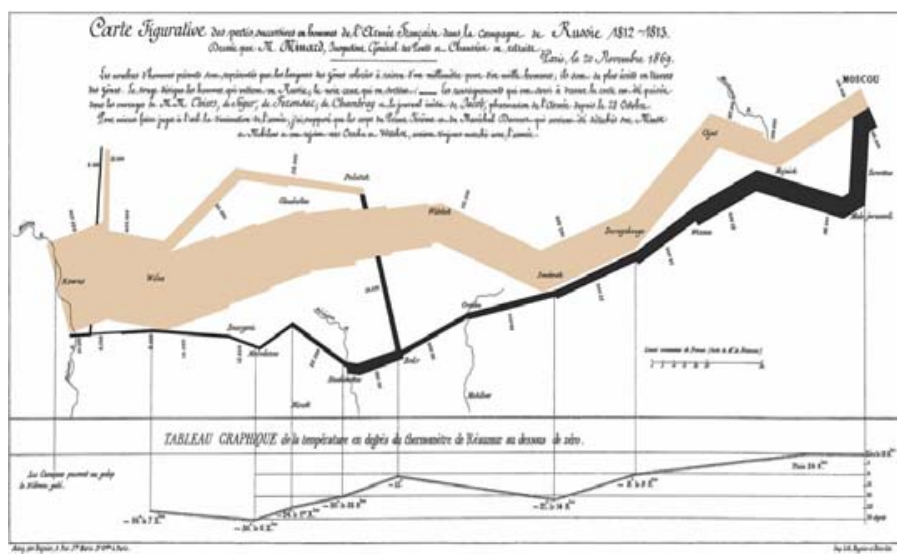

Figura 4: Mapa elaborado por Charles Minard

Com a decisão de representar os jogadores em suas posições, as linhas mais grossas se sobrepõem às mais finas; para contornar esse problema, as linhas têm um efeito de transparência, para que todas possam ser visualizadas.

Finalmente, o rendimento de cada jogador é representado pelo tamanho do círculo. Deve-se tomar o cuidado de considerar que aquilo que deve ser proporcional ao número representado é a área do círculo, e não seu diâmetro. Também foi usado um código de cores para mostrar os jogadores substituídos.

\subsection{Heat maps}

Os mapas de calor, também disponibilizados pela Fifa, mostram em que lugares do campo cada jogador ficou, e podem ser usados para comparar o posicionamento de dois jogadores (Figura 5).

Estes mapas se enquadram no que Jacques Bertin chamou de "mapas para ver" (BERTIN, 1986: 147), ou seja, que permitem, ao contrário dos "mapas para ler", perceber instantaneamente a presença dos jogadores no campo. A representação também obedece às recomendações de Bertin, no que ele chamou de "implantação zonal", através de círculos de diversos tamanhos que geram uma mancha com contornos mais ou menos definidos, dependendo do caso. 


\section{A infografia baseada em dados brutos: design e programação proporcionando uma melhor análise da informação}

\section{Michel Bastos}

$9.429 \mathrm{~m}$ percorridos

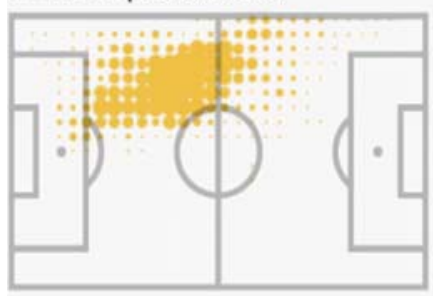

\section{Juan}

$8.323 \mathrm{~m}$ percorridos

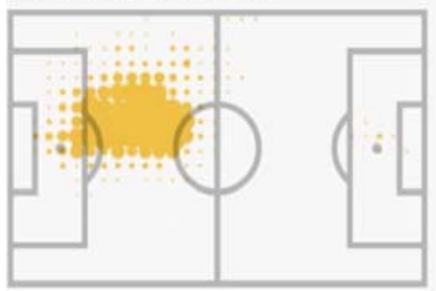

Figura 5: Mapa de calor de quatro jogadores brasileiros (detalhamento da Figura 1)

\subsection{Mapa de concentração do jogo}

Analisa em qual parte do campo se concentrou a posse de bola. Possui características comuns a um gráfico de pizza, já que representa a distribuição do total em porcentagem (Figura 6).

\section{Concentração de jogo}

\section{Posse de bola do Brasil por setores do campo}

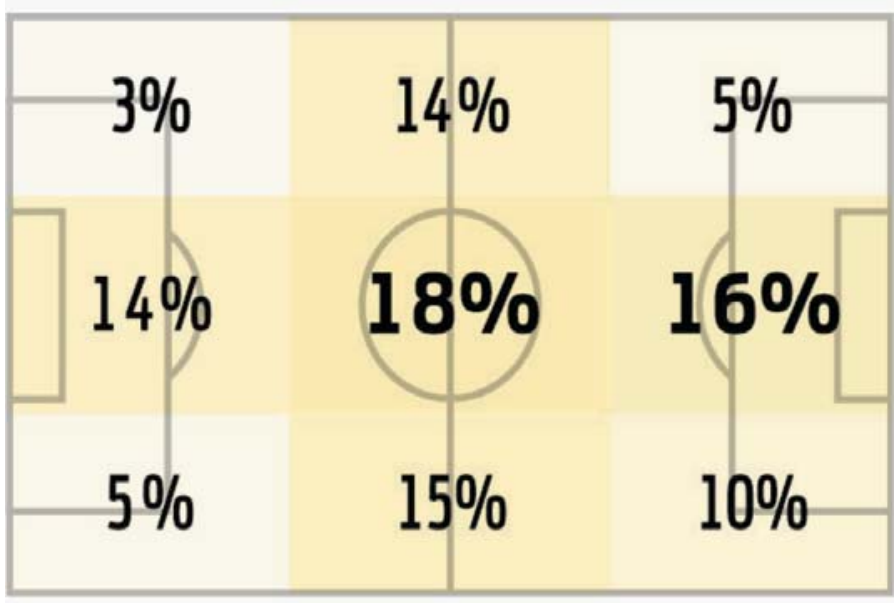

Direção de ataque $\rightarrow$

Figura 6: Mapa de concentração do jogo (detalhamento da Figura 1)

\subsection{Origem dos ataques}

É, em essência, um gráfico de barras, apesar de ser apresentado em forma de setas, o que reforça a ideia da direção do ataque (Figura 7). Mostra para qual lado o time atacou mais.

\section{Origem dos ataques}

\section{Por onde o Brasil mais chegou ao ataque}

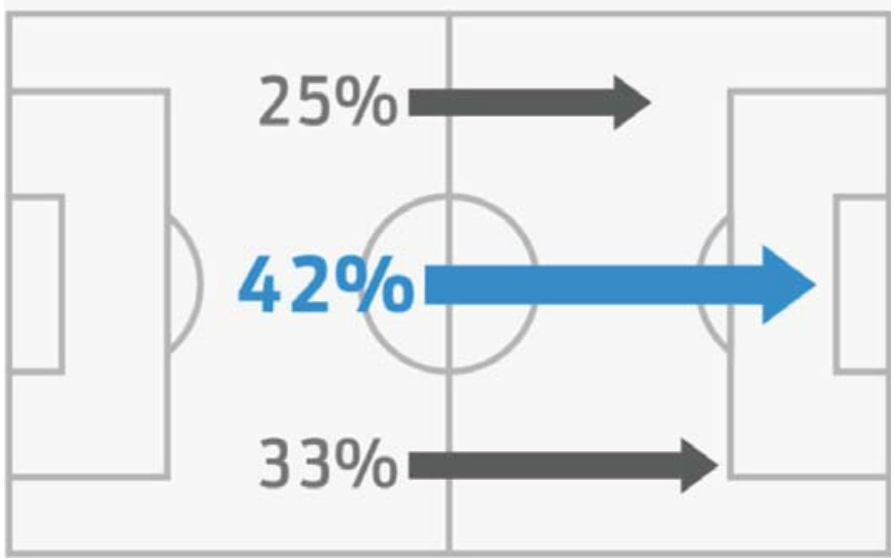

Figura 7: Mapa de origem dos ataques. A seta que representa o maior número tem destaque em outra cor (detalhamento da Figura 1)

\subsection{O campinho e os princípios de design}

Nos três últimos gráficos citados acima (Figuras 5, 6 e 7), pode ser observado o uso da figura do campo de futebol como "grid". Pode-se justificar sua presença citando dois princípios fundamentais do design compilados por Lidwell, Holden \& Butler (2003): affordance e mimicry.

Affordance é uma propriedade do design em que as características físicas do objeto influenciam o modo como é usado. A forma da maçaneta de uma porta, por exemplo, informa - ou deveria - se ela deve ser empurrada ou puxada. Já mimicry, ou mimetismo, é o ato de copiar funções de objetos familiares para se aproveitar de suas affordances. Os autores mencionados a dividiram em vários tipos, sendo a mais próxima desta situação a surface mimicry.

Surface mimicry is defined as making a design look like something else. When a design mimics the surface aspects of a familiar object, the design implies (by its familiar appearance) the way it will function or can be used. An example is the use of computer software icons that are designed to look like folders and documents (LIDWELL, HOLDEN \& BUTLER, 2003: 132). 


\section{A infografia baseada em dados brutos: design e programação proporcionando uma melhor análise da informação}

A figura do campo de futebol se encaixa nesta definição. Com tantos gráficos abstratos que não são dos tipos mais conhecidos, faz-se necessária uma figura reconhecível, que imite algo real, como o campo de futebol. Observa-se, então, uma affordance, que direciona como o gráfico deve ser lido e faz com que o leitor ligue diretamente os fatos presentes no gráfico à sua posição no campo.

Neste contexto, o campo de futebol cumpriria também a função de um grid, como um elemento gráfico que serve de guia para os elementos sobrepostos a ele, como a quadrícula de um mapa ou linhas em uma partitura musical. Sobre grids, Tufte afirmou que "the grid should usually be muted or completely suppressed so that its presence is only implicit' (2001: 112). No entanto, considerando-se sua importância como affordance para que o leitor compreendesse a abstração dos gráficos, foi necessário dar mais protagonismo ao campo de futebol, ao invés de relegá-lo somente à função de grid.

\subsection{Jogador por jogador}

Tabela que mostra estatísticas de chutes a gol, total de chutes, faltas sofridas e cometidas, tempo que ficou em campo, passes certos e total de passes dados, além de um gráfico de barras para a porcentagem de passes bem-sucedidos.

\subsection{Dados gerais}

Tabelas simples, com dados que somente podem ser comparados entre os times, como cartões recebidos, faltas sofridas e cometidas etc.

\subsection{Comparação entre times}

Um gráfico do tipo que Peltzer definiu como "gráficos polares" (Figura 8) e nos quais "as proporções são iguais, ao mesmo tempo em (sic) que se exprimem as diferenças entre elas" (Peltzer, 1991: 129). Estes são amplamente utilizados em vários video games de futebol.

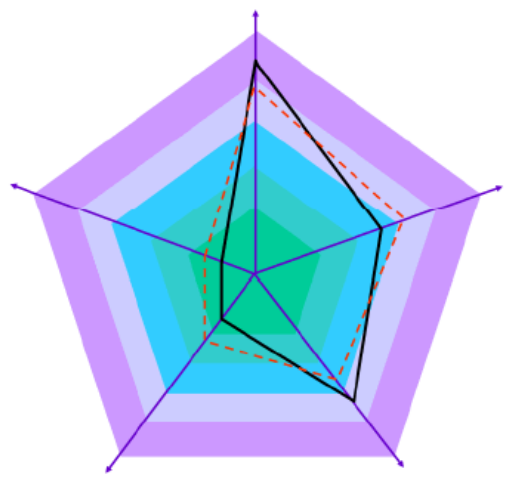

Figura 8: Gráfico no estilo polar, muito utilizado em video games para a observação dos dados de times ou jogadores em suas qualidades específicas

\subsection{A elaboração do mapa de passes}

A elaboração manual do mapa de passes, considerandose a etapa de cálculo das proporções das linhas e superfície dos círculos e o desenho no computador, seria extremamente demorada, especialmente levando-se em conta o pouco tempo entre a liberação dos dados pela Fifa e o fechamento da edição dos jornais. Faz-se necessário encontrar um meio de automatizar esta tarefa.

Para isso, foi escolhida a linguagem de programação "Processing", criada por Ben Fry e Casey Reas em 2001. Concebida inicialmente para servir como um rascunho de software e para ensinar fundamentos de programação em um contexto visual, ela evoluiu rapidamente para uma ferramenta destinada a criar também trabalhos bem finalizados. O software é gratuito, livre e tem suporte a vários formatos de arquivos, inclusive arquivos de gráficos vetoriais, formato necessário para edição e diagramação posterior.

Assim, o primeiro passo foi estabelecer quais dados eram necessários. Para cada jogador, é necessário o número de passes que trocou com os outros e duas coordenadas para determinar sua posição no campo.

A partir da planilha com o número de passes feitos por cada jogador (Figura 9), fornecida pela Fifa, copiam-se essas informações para uma planilha do Excel, onde os números são somados para saber o total de passes trocados entre dois jogadores, independentemente de quem passou para quem, assim como é calculado o rendimento de cada jogador (a partir do número de passes recebidos e feitos).

Em seguida, um programa escrito em Processing (Figura 10) importa os dados gerados pelo Excel e gera o gráfico, em formato PDF. O número de passes é representado pela espessura das linhas entre os jogadores, e o rendimento do jogador é representado através do tamanho do círculo. O número dentro do círculo mostra o total de passes realizados. Códigos de cores adicionais indicam se o jogador foi substituído ou não.

Esse arquivo em PDF, posteriormente, passa por ajustes finais em um software de desenho vetorial, a fim de aperfeiçoar as cores para o processo de impressão.

\section{Considerações finais}

A quantidade de dados disponível graças ao Player Tracking permite gerar visualizações gráficas que resumem melhor os dados que os números brutos. Todas essas representações têm qualidade suficiente para continuar a ser usadas e, inclusive, tornar-se um padrão a ser seguido por diversos meios. O próximo passo é que sejam usadas pelos jornalistas ou leitores como fonte de informação e análise. 


\section{A infografia baseada em dados brutos: design e programação proporcionando uma melhor análise da informação}

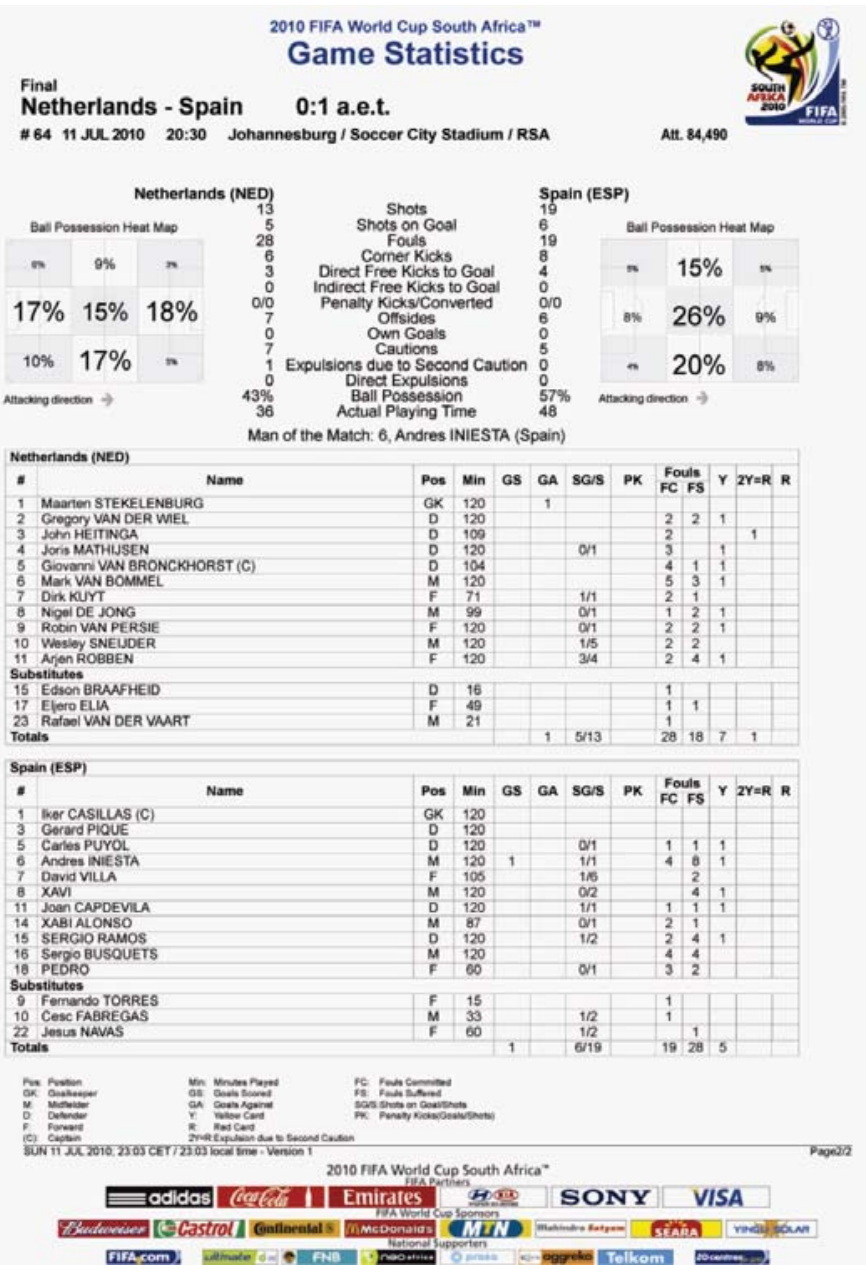

Figura 9: Planilha disponibilizada pela Fifa em seu site. Inclui o número de passes entre os jogadores, dados de concentração de posse de bola e outras informações

No que se refere ao método de trabalho, os jornalistas e infografistas devem pensar em projetar interfaces mais do que em evidenciar dados, para que estes, quando existirem, se revelem por si. Nesses casos, como não se trabaIha com dados previamente existentes, deve-se então prever aqueles que podem surgir e preparar a interface para que estas informações sejam compiladas.

O resultado obtido pelo jornal é um exemplo das vantagens que o jornalismo tem quando é liberado o acesso a dados mais brutos ao invés de dados pré-editados, como os que são encontrados em releases. Essa atitude, afim às filosofias do open data e do open sourcing, pode e deve ser explorada por outras áreas, como órgãos governamentais, que poderiam disponibilizar dados de gastos públicos ou estatísticas de população, ao invés de somente divulgar em releases os números por eles considerados principais. Mais

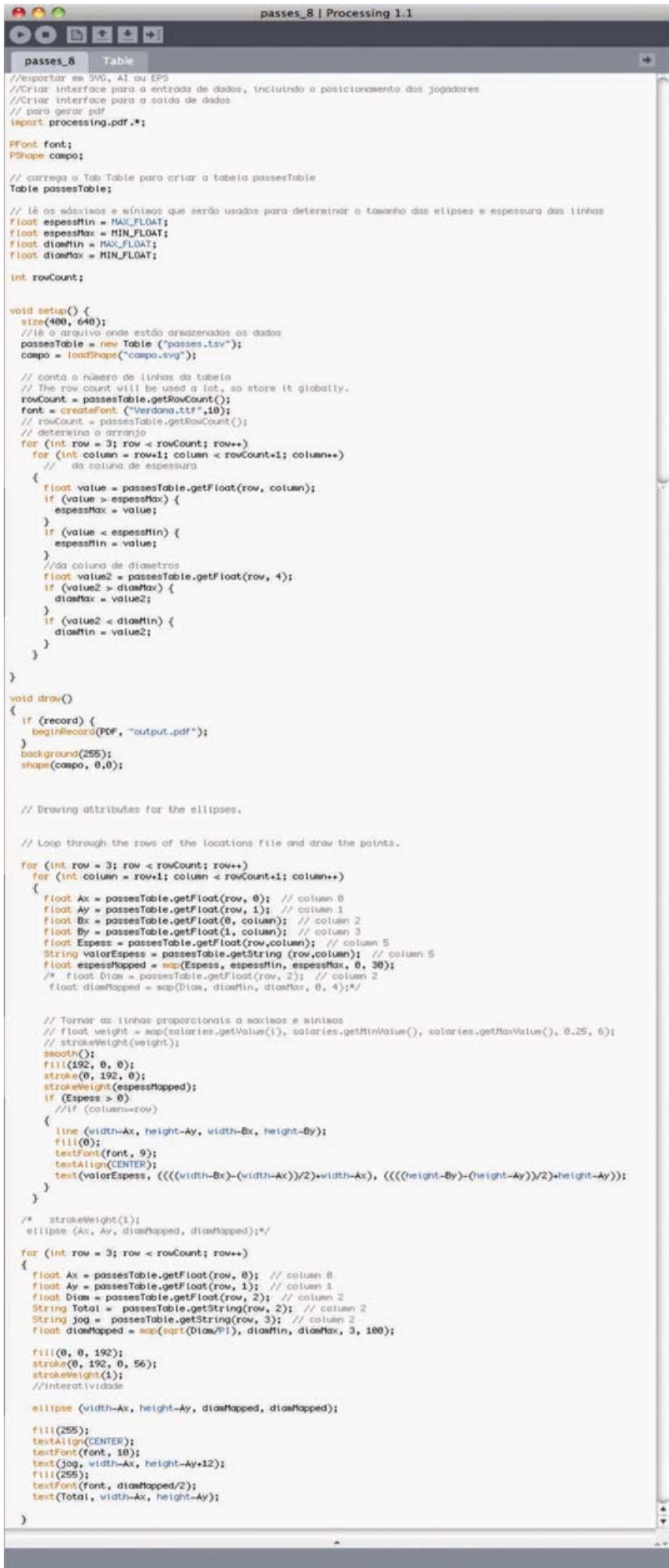

Figura 10: Janela do ambiente de programação Processing, com o código escrito para gerar o mapa de passes a partir dos dados editados em planilha eletrônica 


\section{A infografia baseada em dados brutos: design e programação proporcionando uma melhor análise da informação}

do que disponibilizar os dados, deve-se facilitar o acesso a eles, o que, de certa maneira, foi feito pela Fifa com os dados do Player Tracking, estimulando sua reinterpretação, de modo a gerar novas propostas de visualização e entendimento, seja por parte da editoria de um jornal, seja por parte do leitor consumidor da informação.

\section{Referências}

Begelman, Grigory; Keller, Philipp \& Smadja, Frank. Automated tag clustering: improving search and exploration in the tag space. In: Fifteenth International World Wide Web Conference. Edinburgh: WWW2006, 2006. Disponível em: <http://www.pui.ch/phred/automated_tag_ clustering/>. Acesso em: 10 de dezembro de 2009.

Bertin, Jacques. A neográfica e o tratamento gráfico da informação. Curitiba: UFPR, 1986.

Deforge, Yves. In: Costa, Joan \& Moles, Abraham (orgs.). Imagen didáctica. Barcelona: Ceac, 1991.

De Pablos, José Manuel. Infoperiodismo: el periodista como creador de infografía. Madrid: Síntesis, 1999.
FRY, Ben. Visualizing data. Sebastopol: O'Reilly Media, 2008.

LidWell, William; Holden, Kritina \& ButLeR, Jill. Universal principles of design. Gloucester: Rockport, 2003.

Peltzer, Gonzalo. Jornalismo iconográfico. Lisboa: Planeta, 1991.

Pereira Junior, Luiz Costa. Guia para a edição jornalística. Petrópolis: Vozes, 2006.

TuFTE, Edward. The visual display of quantitative information. Connecticut: Graphic Press, 2001.

Unwin, Antony R.; Theus, Martin \& Hofmann, Heike. Graphics of large datasets - visualizing a million. New York: Springer, 2006. 